\title{
Dyslipidaemia in Rheumatological Autoimmune Diseases
}

\author{
Tracey E. Toms ${ }^{1}$, Vasileios F. Panoulas ${ }^{1}$ and George D. Kitas ${ }^{1,2, *}$ \\ ${ }^{I}$ Department of Rheumatology, Dudley Group of Hospitals NHS Trust, Russells Hall Hospital, Dudley, West Midlands, UK \\ ${ }^{2}$ arc Epidemiology Unit, Manchester University, Manchester, UK
}

\begin{abstract}
Autoimmunity forms the basis of many rheumatological diseases, and may contribute not only to the classical clinical manifestations but also to the complications. Many of the autoimmune rheumatological diseases, including rheumatoid arthritis and systemic lupus erythematosus are associated with an excess cardiovascular morbidity and mortality. Much of this excess cardiovascular risk can be attributed to atherosclerotic disease. Atherosclerosis is a complex pathological process, with dyslipidaemia and inflammation fundamental to all stages of plaque evolution. The heightened inflammatory state seen in conjunction with many rheumatological diseases may accelerate plaque formation, both through direct effects on the arterial wall and indirectly through inflammation-mediated alterations in the lipid profile. Alongside these factors, antibodies produced as part of the autoimmune nature of these conditions may lead to alterations in the lipid profile and promote atherosclerosis. In this review, we discuss the association between several of the rheumatological autoimmune diseases and dyslipidaemia, and the potential cardiovascular impact this may confer.
\end{abstract}

Keywords: Autoimmune disease, dyslipidaemia, rheumatoid arthritis, systemic lupus erythematosus, systemic sclerosis, primary sjogrens syndrome, anti-phospholipid syndrome.

\section{INTRODUCTION}

The complexity and diversity of many rheumatological conditions is often attributed to their underlying autoimmune nature. Autoimmunity contributes to the clinical manifestations, as well as complications of disease and response to treatment. Rheumatoid arthritis (RA) and systemic lupus erythematosus (SLE) have been found to associate with an increased risk for cardiovascular disease (CVD) [1-3], resulting in a significantly shortened lifespan. As a consequence, much speculation and research has focused on the role of both traditional and novel, disease specific, risk factors. In the general population, dyslipidaemia has been shown to be one of the strongest predictors of CVD, with elevated levels of low-density lipoproteins (LDL) forming the primary treatment target according to national guidelines [4]. In this review we discuss the association between several of the autoimmune rheumatological conditions (RA, SLE, primary antiphospholipid sysndrome (primary APS), systemic sclerosis (SSc), and primary Sjogrens syndrome (PSS)) and dyslipidaemia, and the potential impact this has on cardiovascular risk, in particular atherosclerotic plaque formation.

\section{ATHEROSCLEROTIC PLAQUE FORMATION: THE ROLE OF LIPIDS AND INFLAMMATION}

Coronary artery disease develops due to the formation and rupture of atherosclerotic plaques. The term atherosclerosis covers a spectrum of disease ranging from endothelial

\footnotetext{
*Address correspondence to this author at the Department of Rheumatology, Dudley Group of Hospitals NHS Trust, Russells Hall Hospital, Pensnett Road, Dudley, West Midlands, DY1 2HQ, United Kingdom; Tel: +44-1384-244842; Fax: +44-1384-244808; E-mail: gd.kitas@dgoh.nhs.uk or g.d.kitas@bham.ac.uk
}

dysfunction and fatty streak development, through to the formation and rupture of a mature plaque. The development of atherosclerotic plaques is complex. Inflammation is fundamental to all stages of atherosclerotic plaque [5], with an intense bi-directional interaction occurring between lipids and inflammation. Rheumatological autoimmune diseases are associated with a heightened inflammatory state in varying degrees, thus these processes may be accelerated.

Endothelial dysfunction is the initiating step in plaque development [6]. Healthy endothelium exerts a number of vasoprotective effects such as vasodilation, suppression of smooth muscle cell growth and inhibition of inflammatory responses, thereby helping to protect against atherosclerosis. Nitric oxide mediates many of these effects by inhibiting platelet aggregation and LDL oxidation, as well as opposing the effects of endothelium-derived vasoconstrictors [7]. Endothelial damage occurs when the fine balance between vasoconstrictive and vasodilatory pathways is disrupted. Although endothelial dysfunction is likely to be a multifactorial process, the major cardiovascular risk factors such as hypercholesterolaemia, hypertension, diabetes and smoking have been implicated via their ability to increase the production of reactive oxygen species [8]. It is postulated that the increase in reactive oxygen species may in turn reduce endothelial nitric oxide (NO) availability $[9,10]$. Multiple lipid abnormalities have been associated with endothelial dysfunction. Hypercholesterolaemia has been shown to cause focal activation of the endothelium in medium and large arteries and has been associated with an increased number of monocytes entering the intima [11]. High levels of oxidised LDL (oxLDL) may down regulate endothelial NO synthase (eNOS), thus reducing available NO and restricting coronary vasodilation [12]. High levels of circulat- 
ing triglycerides (TGs) may also damage the endothelium via their oxidative charge and result in disruption of the normal NO pathway $[13,14]$. Studies into the effects of lipoprotein (a) $(\operatorname{Lp}(\mathrm{a}))$ have shown elevated levels to be inversely correlated with small artery compliance and NO production [15, 16]. High levels of systemic inflammation may also disrupt endothelial homeostasis via the NO pathway, by reducing the expression of eNOS and increasing the expression of inducible NO synthase producing a net excess of NO [17]. Too much nitric oxide can also be deleterious to the endothelium, thus a very fine balance of $\mathrm{NO}$ needs to be maintained in order to preserve and protect the endothelium [18].

Due to the increased permeability of the dysfunctional endothelium, excess LDL infiltrates the artery wall and is retained in the intima by matrix components. LDL then undergoes modification and oxidation, inducing the endothelial cells to express leukocyte adhesion molecules [19] and initiating an inflammatory response in the artery wall [20]. The contribution of oxLDL particles to the development of atherosclerosis is summarised in Fig. (1).

The first cells attracted to the activated endothelium are platelets [21]. They adhere via glycoproteins on their surface, triggering further endothelial activation resulting in leukocyte infiltration [22]. Once in the sub-endothelial space, monocytes are transformed to macrophages and subsequent incorporation of LDL via endocytosis by scavenger receptors (CD36 and others) differentiates them further into foam cells. The accumulation of foam cells, smooth muscle cells and $\mathrm{T}$ cells results in the formation of a fatty streak (Fig. 2a), the earliest recognisable lesion of atherosclerosis [23].

Fatty streaks can progress to form intermediate and advanced lesions (Fig. 2b), by amplification of the processes involved in formation of fatty streaks. The advanced lesions tend to form a protective fibrous cap that walls off the lesion from the lumen. Advanced plaques have a lipid-rich necrotic core containing an abundance of tissue factor, which plays a vital role in thrombus formation upon plaque rupture [24].

Plaque instability and rupture occurs due to uneven thinning or erosion of the fibrous cap. Destabilisation and degradation of the fibrous cap results from the production of inflammatory cytokines, proteases, radicals, coagulation factors and vasoactive molecules, from activated macrophages, $\mathrm{T}$ cells and mast cells [25]. The above events lead to plaque rupture, exposing the contents of the core of the plaque to the circulating blood and subsequent activation of the clotting cascade. As the thrombus forms and enlarges, the arterial lumen narrows and ischaemic symptoms may present.

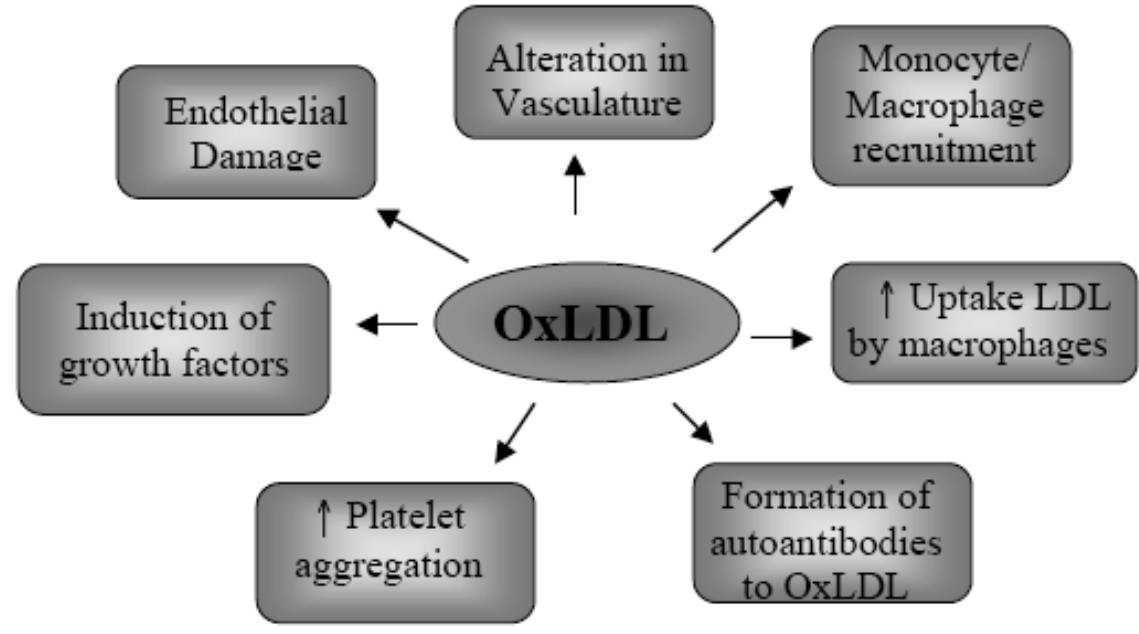

Fig. (1). The role of oxidised LDL.

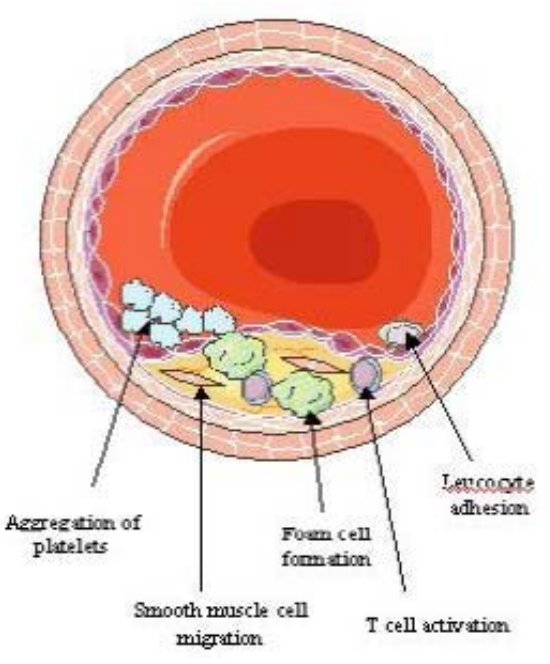

Fig. (2a). Fatty Streak formation.

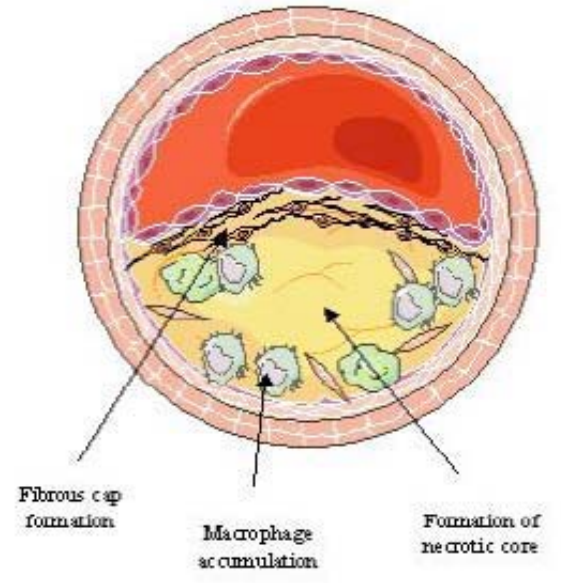

Fig. (2b). Advanced plaque formation. 


\section{RHEUMATOID ARTHRITIS}

RA affects approximately $1 \%$ of the adult population in the United Kingdom [26]. RA predominately affects the synovial joints resulting in joint pain, swelling and stiffness, but can also produce an array of clinical manifestations as part of the systemic nature of the disease, ranging from constitutional symptoms to organ involvement. Uncontrolled inflammation can confer a large personal, socio-economic, and psychosocial burden as a consequence of significant joint destruction and deformity.

RA patients have a reduced life expectancy and increased mortality rates compared to the general population [1, 3], with CVD accounting for approximately half of all RA deaths [27]. A recent meta-analysis has shown that the risk of death from CVD is almost $50 \%$ higher in RA patients compared to healthy controls [28]. Although CVD in RA can present in many guises (e.g. congestive heart failure, myocardial infarction (MI) and pericarditis), it is those with an underlying ischaemic pathology that pose the greatest mortality risk, as a consequence of atherosclerotic plaque formation [29-31]. Despite this, atherosclerotic disease remains under-diagnosed in RA due to an often atypical or silent presentation [32]. Although the mechanisms responsible for this phenomenon still need to be elucidated, differences in atherosclerotic plaque structure may be responsible. Atherosclerotic plaques of RA patients differ morphologically to those observed in the general population, with less histological evidence of atherosclerosis but far greater plaque instability [33]. Such differences may also offer a potential explanation for the higher fatality rates associated with MI in RA and the increases seen in post MI complication rates [34].

Atherosclerosis in RA may be enhanced through several pathways. Traditional cardiovascular risk factors such as hypertension [35, 36] and obesity [37-39] may occur more frequently in RA or be modified through disease specific mechanisms. In addition, novel risk factors such as systemic inflammation, hyperhomocysteinaemia [40] and activation of the coagulation pathway [41] may further escalate atherosclerotic plaque formation. In fact, the impact of systemic inflammation on CVD is so great it has now been recognised as an independent cardiovascular risk factor in the general population $[42,43]$. Although there is a degree of interplay between all of the risk factors, systemic inflammation appears to be fundamental to virtually all. Furthermore, RA patients may be genetically predisposed to the development of atherosclerosis and myocardial infarction [44, 45].

Dyslipidaemia is highly prevalent in RA affecting between $55-65 \%$ of patients $[46,47]$ and can manifest in RA patients with both early [48] and advanced disease [49]. One retrospective study on 1078 blood donors has suggested that the lipid profile may be altered prior to the onset on RA [50]. This study demonstrated that the 79 blood donors who later developed RA had significantly higher total cholesterol (TC), triglyceride (TG), apolipoprotein B (apoB) levels, and lower high density lipoprotein (HDL) levels up to ten years prior to the onset of RA compared to matched controls. This suggests that alterations in the lipid profile may render people more susceptible to the future development of RA [51] or that RA patients are genetically predisposed to the develop- ment of RA related dyslipidaemia or that the transcription of these genes is altered by persistent inflammation.

Although dyslipidaemia in RA may be partially governed by a genetic predisposition, it is also influenced by an array of other factors including disease activity [52], reduced physical activity secondary to pain and disability [53], and drug therapy $[54,55]$. In untreated RA the lipid profile is characterised by suppression of HDL and TC levels [51, 56, 57]. At first glance this appears to produce a less atherogenic profile, however, HDL levels fall disproportionately more compared to TC levels resulting in an increased atherogenic index (TC:HDL ratio) [48, 56, 58]. The largest study to compare the lipid profiles of untreated RA patients to a control group is the National Health and Nutrition Examination Survey (NHANES III) [54]. This study included 104 patients who were naïve to disease modifying anti-rheumatic drugs (DMARDs) and glucocorticoids (GCs). It confirmed a significant fall in HDL and apolipoprotein A-I (apoAI) levels but failed to demonstrate any significant changes in other lipid levels. Current data exploring the effects of heightened disease activity on TG and low density lipoprotein (LDL) levels is conflicting with some studies reporting a positive association [56] and others a negative association [59, 60]. These discrepancies may be a consequence of limitations of study design, including small study size, differences in baseline characteristics, and incomplete adjustment for confounders.

For many years, apolipoproteins have been recognised as potential markers for CVD in the general population [61]. This is rather unsurprising, as apolipoproteins are found in conjunction with lipid particles (e.g. Apo-AI with HDL and Apo-B100 with LDL). However, emerging evidence now indicates a superiority of measuring apolipoproteins as CVD risk factors, rather than their lipid counterpart (e.g. ApoB rather than LDL) [62]. In RA, Apo-AI levels decrease [48, 52, 54, 63], mirroring the supression in HDL observed in active RA. Although, Apo-B levels have also been reported to be reduced with high levels of inflammation [64] this is to a lesser degree than Apo-AI levels [48, 52, 64].

For many years individual lipid levels have formed the basis of CVD risk stratification algorithms [4, 65]. However, the use of lipid and apolipoprotein ratios is gaining popularity as they have been shown to confer a greater predictive value of first myocardial infarction than individual lipid levels in the general population $[66,67]$. The lipid ratios shown to be useful in risk stratification, include TC:HDL ratio [68], LDL:HDL ratio [69] and ApoB: ApoA1 ratio [70]. All three lipid ratios have been reported to increase in active RA [48, 56]. In addition, lipid ratios have been considered as an attractive alternative method of risk stratification in RA as they may overcome the inflammatory mediated fluctuations in individual lipid parameters [71].

Lipoprotein (a) ( $\mathrm{Lp}(\mathrm{a}))$, is an LDL particle that is bound to apolipoprotein (a), by a disulphide bond with Apo-B100. Current evidence suggests $\operatorname{Lp}(a)$ is a key factor in the development of atherosclerosis [72, 73]. The structure of $\mathrm{Lp}(\mathrm{a})$ may mechanistically contribute to atherosclerotic plaque formation, through its structural similaririties with plasminogen. $\mathrm{Lp}$ (a) competes with plasminogen for its binding site, and stimulates the production of plasminogen activator in- 
hibitor -1 (PAI-1), with the net effect of enhancing plaque thrombosis [74]. In addition, $\mathrm{Lp}(\mathrm{a})$ has been shown to interact with other established cardiovascular risk factors [75], including lipid parameters (HDL and LDL) [76]. In RA, several studies have demonstrated a significant increase in $\mathrm{Lp}(\mathrm{a})$ levels $[48,54,56,77,78]$, which in the majority of studies appears to shadow changes in LDL $[48,54,56]$. Although inflammation may partially control these changes in $\mathrm{Lp}(\mathrm{a})$, genetic factors may also contribute [79]. Apolipoprotein (a) has several phenotypic variations, due to allelic differences. A recent study has demonstrated that RA patients have a higher frequency of the S3 allele compared to healthy controls (70\% vs 39.5\%) [79]. The presence of the S3 allele associates with a lower molecular weight of Apo(a) [80]. Furthermore, there is an inverse association between the molecular weight of $\mathrm{Apo}(\mathrm{a})$ and $\mathrm{Lp}$ (a) levels [81], thus potentially accounting for the increased $L p(a)$ levels observed in RA.

Further, intricate changes in lipid metabolism have been described in RA. High levels of oxidative stress can occur in conjunction with the chronic inflammatory burden of RA [66]. Lipid particles (in particular LDL) exposed to this environment both within the synovial fluid and the plasma of RA patients are susceptible to oxidative modification [82, 83]. Once oxidised, the LDL particles exhibit enhanced proatherogenic properties, through their ability to more readily infiltrate the arterial wall, form foam cells and initiate a localised inflammatory response.

Lipid/lipoprotein particles are not uniform and in healthy individuals are found in a range of sizes and densities. Such diversity is crucial for maintaining the normal pathways of lipid metabolism such as reverse cholesterol transport. However, these structural differences also dictate the atherogenicity of each of the particles. Small dense LDL particles (LDL3) are more prone to oxidation and more readily able to infiltrate the arterial wall than their larger counterparts [84], whereas smaller HDL particles (HDL2) are more successful in performing reverse cholesterol transport and thus confer greater cardio-protection [85]. In RA, the limited available data appears to suggests that RA patients have a more proatherogenic lipoprotein subfraction profile with higher levels of small dense LDL particles and lower levels of smaller HDL particles [86]. Alongside this, the balance of proatherogenic/anti-atherogenic HDL may be further disrupted through suppression of enzymes including paraoxonase 1 (PON) [87].

In summary, although we have a basic understanding of the effects of RA on the standard lipid profile (TC, LDL, TG and HDL levels) (Fig. 3), our understanding of dyslipidaemia in RA remains far from complete. Further large-scale studies are required to investigate the changes in lipid/lipoprotein structure and function and to establish the relative contribution of dyslipidaemia in its entirety to CVD in RA.

\section{SYSTEMIC LUPUS ERYTHEMATOSUS}

Systemic lupus erythematosus (SLE) is a multisystem autoimmune disease that predominately affects premenopausal females, with a peak age of onset between 20-30 years. The condition can manifest with a broad spectrum of clinical signs and symptoms, ranging from relatively minor symptoms such as arthralgia to life-threatening organ involvement. SLE has a relapsing remitting course, often resulting in acute 'flares' characterised by a dramatic worsening of clinical symptoms, a heightened inflammatory response and elevated auto-antibody levels.

SLE confers a massive CVD risk, which is far greater than described in other autoimmune diseases. Patients with a disease duration greater than 5 years have been reported to have 52 times greater risk of suffering a myocardial infarction than matched controls [2]. In fact, the processes underlying atherosclerosis are so advanced that subclincal atherosclerosis has even been reported in the paediatric age range

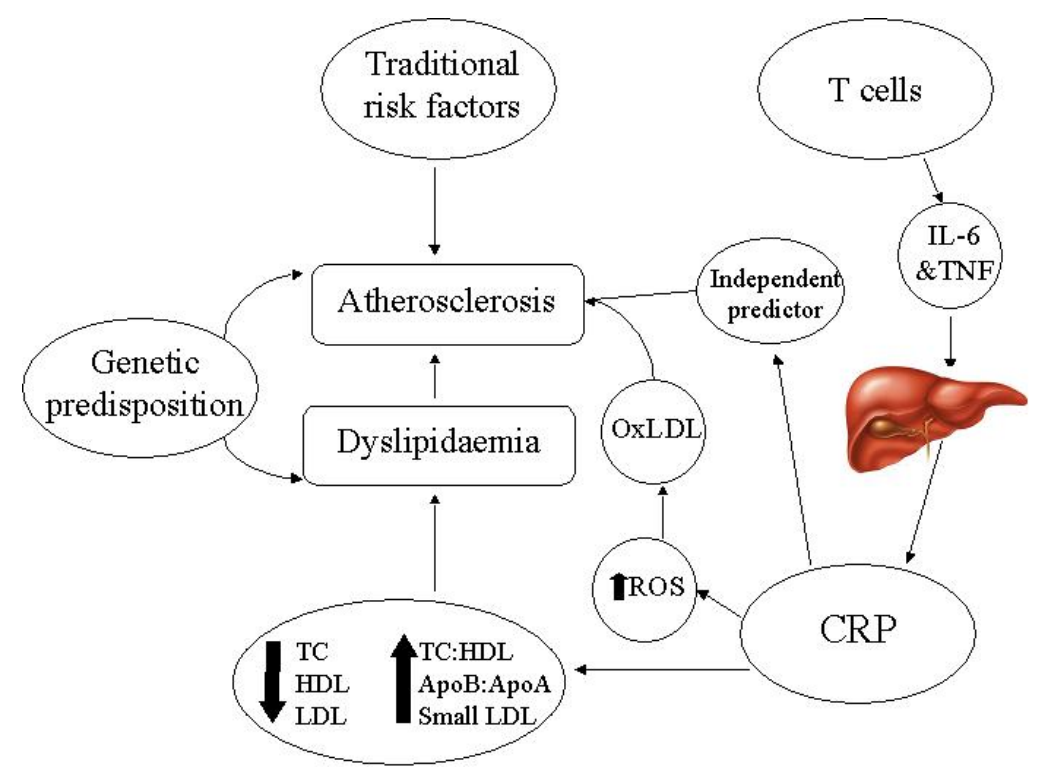

Fig. (3). The main mechanisms contributing to dyslipidaemia and atherosclerosis in rheumatoid arthritis. IL-6: Interleukin-6, TNF: Tumour necrosis factor, CRP: C reactive protein, ROS: Reactive oxygen species, OxLDL: oxidised low-density lipoproteins, TC: total cholesterol, HDL: High-density lipoproteins, LDL: low-density lipoproteins, ApoB:ApoA: apolipoproteinB: apolipoproteinA ratio, TC:HDL: total cholesterol: high-desnity lipoprotein ratio. 
[88]. Thus, it is unsurprising that SLE has now been identified as an independent risk factor for the development of endothelial dysfunction, the earliest vascular change in the process of atherosclerotic plaque formation [89]. It is now clear that although traditional risk factors, including dyslipidaemia may be more frequent in SLE these alone do not fully account for the excess cardiovascular morbidity and mortality [90]. Several disease specific factors have been implicated including inflammation, oxidative stress and the presence of anti-phospholipid antibodies [91, 92].

The dyslipidaemia seen in conjunction with SLE is more typical of that described in the general population in relation to CVD, with elevations in TG, LDL, TC and ApoB and a parallel fall in HDL levels [93]. Although the alterations in the lipid profile appear to be exacerbated by active disease, significant changes have been observed in patients with inactive disease [94, 95], thus reflecting that factors other than inflammation may be at play (Fig. 4). Although the lipid profile seen in conjunction with active SLE (elevations in TC and LDL levels) appears to differ from that seen in active RA, there are also similarities (Table 1). Firstly, inflammatory mediators such as CRP and ESR have been shown to suppress HDL levels and increase TG levels [96]. Secondly, other markers of disease activity including the systemic lupus erythematosus disease activity index (SLEDAI) [94], C3d (a specific serological marker of lupus activity) levels [93], anti-double stranded DNA (dsDNA) levels [97] and levels of inflammatory cytokines have been found to associate with lipid levels [98, 99]. One potential inflammationmediated mechanism that is thought to control some of the lipid alterations seen in SLE, is reduced activity of the enzyme lipoprotein lipase (LPL) [100], which may be governed by circulating inflammatory mediators (e.g. tumour necrosis factor and interleukin-6 (IL-6) [101], and antibodies directed against LPL (anti-LPL) [102]. LPL is responsible for the catabolism of chylomicrons and very low density lipoproteins (VLDL), thus suppression of LPL activity results in an accumulation of TG-rich particles [100]. The presence of cytokines including TNF- $\alpha$ and IL-6 also triggers hepatic production of CRP, which may further exacerbate HDL suppression. The high levels of circulating IL-6 have been shown to inversely correlate with HDL levels.

High levels of systemic inflammation found in conjunction with SLE result in an increased burden of oxidative stress [103]. Increased oxidative stress can trigger a broad range of pro-atherogenic lipid modifications, including the formation of oxidised LDL (oxLDL), conversion of antiinflammatory HDL into pro-inflammatory HDL [104], and altering the function of key enzymes involved in lipid metabolism and function [93]. The oxidation of LDL is particularly interesting in SLE, as oxidation affects not only the lipid component of the lipoprotein but also components such as cardiolipin. Antibodies directed against oxidised cardiolipin (anti-phospolipid (aPL) antibodies) are increased in a proportion of SLE patients, predominately those exhibiting features of co-existant anti-phospholipid syndrome (APS) [105]. There are three aPL antibodies found in SLE 1) Lupus anticoagulant 2) anti-cardiolipin antibodies and 3) antibodies to $\beta_{2}$ glycoprotein [105]. The presence of aPL antibodies confers an increased thrombotic risk in SLE [106], thus atherosclerotic plaque rupture often has devastating implications due to vessel occlusion as a consequence of massive thrombus formation. The presence of IgG anti-cardiolipin antibodies have also been associated with low levels of HDL and apolipoprotein A-1, thus further escalating CVD risk [107].

SLE patients have high levels of antibodies against oxLDL, which may accelerate the uptake of LDL into the endothelial wall [108]. In addition, there is expanding evidence that antibodies against oxLDL may cross-react with IgM and IgG anticardiolipin antibodies [108, 109], thus further escalating CVD risk. Of particular interest oxLDL forms complexes with $\beta 2$-glycoprotein I, which have been shown to amplify arterial thrombosis in patients with APS [110], and this may also be a pro-atherogenic mechanism in SLE patients who are positive for APS antibodies.

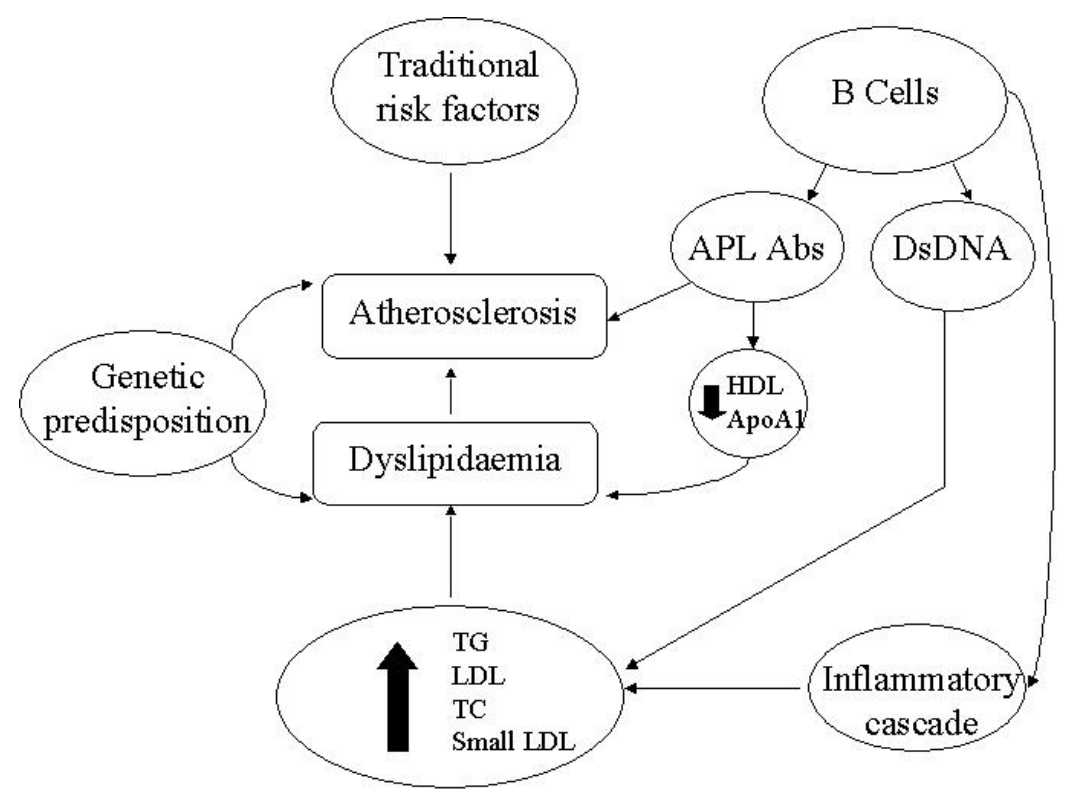

Fig. (4). The main mechanisms contributing to dyslipidaemia and atherosclerosis in systemic lupus erythematosus. HDL: Highdensity lipoprotein, ApoA1: apolipoprotein A1, APL Abs: anti-phospholipid antibodies, DsDNA: double stranded DNA, TG:triglycerides, LDL: low-density lipoproteins, TC: total cholesterol. 
Table 1. A Summary of the Classical Lipid/Lipoprotein Profile in Autoimmune Rheumatological Conditions

\begin{tabular}{|l|c|c|c|c|c|c|c|c|c|}
\hline & TC & HDL & LDL & TG & Lp(a) & oxLDL & TC:HDL & LDL:HDL & ApoB:ApoA1 \\
\hline \hline RA & $\downarrow$ & $\downarrow \downarrow$ & $?$ & $?$ & $\uparrow$ & $\uparrow$ & $\uparrow$ & $\uparrow$ \\
\hline SLE & $\uparrow$ & $\downarrow$ & $\uparrow$ & $\uparrow \uparrow$ & $\uparrow$ & $\uparrow$ & & \\
\hline APS & $\leftarrow$ & $\leftarrow$ & $\leftarrow \rightarrow$ & $\uparrow$ & $\leftarrow \rightarrow$ & & & \\
\hline PSS & $\downarrow$ & $\downarrow$ & $\leftarrow \rightarrow$ & $\leftarrow \rightarrow$ & & & $\leftarrow$ & \\
\hline SSc & $\leftarrow \rightarrow$ & $\leftarrow \rightarrow$ & $\leftarrow \rightarrow$ & $\uparrow$ & $\uparrow$ & $\uparrow$ & & \\
\hline
\end{tabular}

RA: rheumatoid arthritis, SLE: systemic lupus eythematosus, APS: anti-phospholipid syndrome, PSS: primary sjogrens syndrome, SSc: systemic sclerosis, TC: total cholesterol, HDL: high density lipoproteins, LDL: low density lipoproteins, TG: triglycerides, Lp(a): lipoprotein (a), oxLDL: oxidised low density lipoproteins, TC:HDL: total cholesterol:high density lipoprotein ratio, LDL:HDL: low density lipoprotein:high density lipoprotein ratio, ApoB: ApoA1: apolipoprotein B: apolipoprotein A1 ratio. $\leftarrow \rightarrow=$ no change, $\downarrow=$ decreased levels, $\uparrow=$ increased levels, $?=$ conflicting data $=$ no data

Several studies have investigated the lipoprotein subfraction profile in SLE, however, the impact of such changes on the development of subclinical atherosclerotic plaque formation and cardiovascular events remains to be established [93, $111,112]$. The first study determined the LDL lipoprotein subfraction profile in 53 patients with SLE and 53 age and sex matched healthy controls, using the method of disc polyacrylamide gel electrophoresis [93]. SLE patients had increased levels of small dense LDL subfractions, which were found to associate with high levels of oxidative stress and elevated CRP levels. Two further studies adopted the method of nuclear magnetic resonance (NMR) spectroscopy, allowing quantification of both HDL and LDL subfractions [111, 112]. The study by Hua et al., examined lipoprotein subfractions in 26 female SLE patients with a history of CVD (myocardial infarction, angina, thromoembolic stroke, or intermittent claudication), 26 age matched SLE patients without CVD and 26 age and sex matched controls [112]. This study demonstrated that SLE patients with a history of CVD had higher levels of small dense LDL than the healthy control population, however the same was not found for SLE patients without CVD. Lower levels of the small 'cardioprotective' HDL subfractions were found in SLE patients (with and without CVD) compared to healthy controls. Chung et al. also performed lipoprotein subclassification using NMR spectroscopy in 105 SLE patients (without a history of CVD) and 77 healthy controls [111]. The levels of small dense LDL did not significantly differ between SLE patients and controls and were not found to associate with coronary calcification. The differences observed in the lipoprotein subfraction profile between these studies can be attributed to differences in baseline demographics, the underlying CVD risk, drug therapy and methodology, as well as small study size. Further longitudinal studies are required to elucidate the role (if any) of lipoprotein subfractions to CVD in SLE.

A further two studies have focused on HDL subfractions $[113,114]$. Both have demonstrated an atherogenic profile with increased levels of HDL3 and reduced levels of HDL2 compared to healthy controls.

$\mathrm{Lp}$ (a) levels have been shown to be substantially increased in SLE patients with studies reporting them to be almost double those seen in matched control populations [115-118]. This appears to be independent of the effects of disease activity, thromobotic events, the presence of aPL antibodies and glucocorticoid use [115]. Furthermore, SLE patients with a history of vascular disease have been found to have higher Lp(a) levels than SLE patients without a history of vascular disease [117, 119], thus indicating a causative role. Unfortunately, all studies to date are limited by the small sample size and cross-sectional design, thus making it impossible to draw conclusions regarding the impact of Lp(a) on CVD in SLE. Similar to the findings in RA, genetic factors are major determinants of elevated $L p(a)$ levels in SLE, with only the small apolipoprotein (a) phenotypes found to significantly predict Lp(a) levels in SLE [118].

Data regarding changes in apolipoprotein levels and their relative contribution to CVD in SLE is sparse. One study comparing the lipid profile in 53 premenopausal SLE patients to 45 healthy controls reported significant elevations in both ApoA1 and apoB levels, with apoB levels found to associate with the presence of proteinuria [120]. A further study involving 46 SLE patients and 30 matched controls reported conflicting findings, with similar ApoA1 levels observed in both groups [113]. The effects of treatment with glucocorticoids on apoplipoprotein levels also remains a matter of some debate, with one study demonstrating no change in ApoA1 levels [113] and another demonstrating an increase in apoA1 levels [121]. To date there have been no studies assessing the predictive value of apolipoproteins in CVD risk stratification.

\section{ANTI-PHOSPHOLIPID SYNDROME}

The Antiphospholipid syndrome (APS) is characterised by a combination of arterial and venous thrombosis, recurrent miscarriages, and thrombocytopenia. Although APS is most commonly found as an overlap syndrome with SLE, it is also recognised as an independent clinical entity (primary APS) [122].

To date, there is much speculation as to whether primary APS patients are at greater risk of atherosclerotic plaque formation than the general population. Some of this uncertainty stems from the significant limitations of the available study data, such as small study size and poor methodology [123], but may also be attributed to the lack of evidence to support a role of APL antibodies in atherothrombosis formation in non-SLE patients with MI [124, 125]. However, several studies on primary APS patients have demonstrated subclinical vascular changes consistent with endothelial dys- 
function and early atherosclerotic plaque formation including impaired flow mediated dilatation and increased carotid intima-media thickness [126-128], respectively. Unfortunately, there is a lack of direct epidemiological evidence supporting a higher CVD morbidity or mortality in primary APS.

In line with a relative lack of available information on CVD in primary APS, data on dyslipidaemia in primary APS is also sparse. No studies have specifically been designed to assess dyslipidaemia in primary APS, however, a few small studies have commented on the lipid profile [128, 129]. The first study to comment on the lipid profile in primary APS, did not find any significant differences between TC, HDL, LDL, TG, ApoA1, ApoB, or Lp(a) levels compared to healthy controls [128]. A second study by Medina et al. [129] has reported conflicting findings with a significant increase in TG levels in patients with primary APS compared to healthy controls. These differences can be explained by differences in study size, baseline demographics, inclusion/exclusion criteria and auto-antibody status. Based on these studies alone we are unable to get a true representation of the extent of dyslipidaemia in primary APS (if any) and the impact this may have on CVD, thus further studies are required to address this.

\section{SJOGRENS SYNDROME}

Primary Sjogren's syndrome (PSS) is characterised by chronic inflammation of exocrine glands, resulting in ocular and oral dryness. Although a systemic disease, the inflammation associated with the condition is much less than that seen with RA or SLE. The prevalence of CVD in PSS remains to be established. However, examination of the carotid intimamedia thickness of patients with PSS compared to controls has demonstrated a higher prevalence of subclinical atherosclerosis (PSS 49\% vs controls 11\%) [130]. In this study, the presence of anti-SSA antibodies and leucopenia, but not alterations in the lipid profile, were found to associate with subclincal atherosclerosis.

Two investigators have specifically examined the lipid profile in PSS in relation to inflammation and autoantibody status. The first study conducted by Lodde et al. compared serum lipid profiles in 44 patients with PSS to 12 control patients with oral dryness failing to fulfil the diagnostic criteria for PSS [131]. This demonstrated significantly lower TC and HDL levels in patients with PSS. Other lipid parameters, including lipid ratios (LDL, TG, TC:HDL ratio and LDL:HDL ratio) were not different between patients and control subjects. The levels of TC and HDL in the PSS patients were not found to associate with inflammation (CRP or ESR), however both were found to associate with IgG levels. Alongside this, TC and HDL levels were found to significantly inversely correlate with anti-SSA and anti-SSB antibodies, respectively. A second small study (37 females with PSS and 35 age-matched female controls) confirmed a decrease in HDL levels in patients with PSS, but other lipid components did not significantly differ [132]. HDL levels did not associate with inflammation or auto-antibody status.

Although patients with PSS exhibit some alterations in the lipid profile that are typical of those seen in RA and SLE, including suppression of HDL levels, the mechanisms underlying this need to be examined in more detail. Inflammation appears to be an unlikely culprit due to a lack of association seen in these studies. However, due to the comparative lowgrade inflammation seen in PSS much larger scale studies and more sensitive methodology (high sensitivity CRP) may be required to provide the power to detect such a relationship.

\section{SYSTEMIC SCLEROSIS}

Systemic sclerosis (SSc) is a condition characterised by skin fibrosis that advances proximally from the distal extremities. In addition, patients with SSc can develop complications arising from organ involvement, including pulmonary fibrosis, renal failure and vasculopathy. The vascular involvement in SSc has traditionally been thought to be due to microvascular disease $[133,134]$, however, evolving data suggests an increased prevalence of macrovascular disease as well [135]. Patients with SSc have a fourfold increase in mortality compared to the general population, with approximately a third of all deaths due to cardiovascular causes [136]. Although, peripheral vascular disease (PVD) has been reported to be almost 5 times higher amongst patients with SSc than the general population [137, 138], carotid intimamedia thickness (IMT), a marker of subclinical atherosclerosis, has been found not to differ significantly between cases and controls [139, 140]. Irrespective of these findings, studies have demonstrated evidence of increased endothelial dysfunction in SSc patients compared to controls, as measured by flow-mediated dilatation [140, 141]. In addition, endothelial dysfunction has been shown to improve following endothelin receptor blockade in SSc [142]. Markers of arterial stiffness such as pulse wave velocity and aortic augmentation index have also been shown to be higher in SSc patients than in a control population [141].

Dyslipidaemia and its contribution to vascular disease/endothelial dysfunction in SSc remains relatively unstudied with only a handful of small studies attempting to address this $[135,139,143]$. The changes in the lipid profile in SSc appear to be subtle, with many of the conventional lipid parameters reported to remain unchanged and only a significant increase in TG levels being witnessed by some investigators [143, 144]. The hypertryglyceridaemia in SSc may be mediated through reduced LPL activity as a consequence of the formation of anti-LPL antibodies [144]. However, when delving deeper it is apparent that further potentially pro-atherogenic changes including enhanced oxidation of LDL [145] and increased Lp(a) levels [146] occur. Increased levels of circulating adhesion molecules have also been noted in SSc. Although these appear to occur in conjunction with endothelial dysfunction [147, 148], to date no direct associations have been made between adhesion molecules and atherosclerotic disease in SSc.

In summary, patients with SSc may have an increased risk of CVD, but this requires further clarification in largescale studies specifically designed to assess this. In addition SSc patients appear to harbour several alterations in the arterial wall including increased arterial stiffness and endothelial dysfunction, however, the contribution of dyslipidaemia to such changes, if any, requires further investigation.

\section{DRUG THERAPY AND DYSLIPIDAEMIA}

The management of many of the autoimmune rheumatological conditions relies upon the use of immunosuppres- 


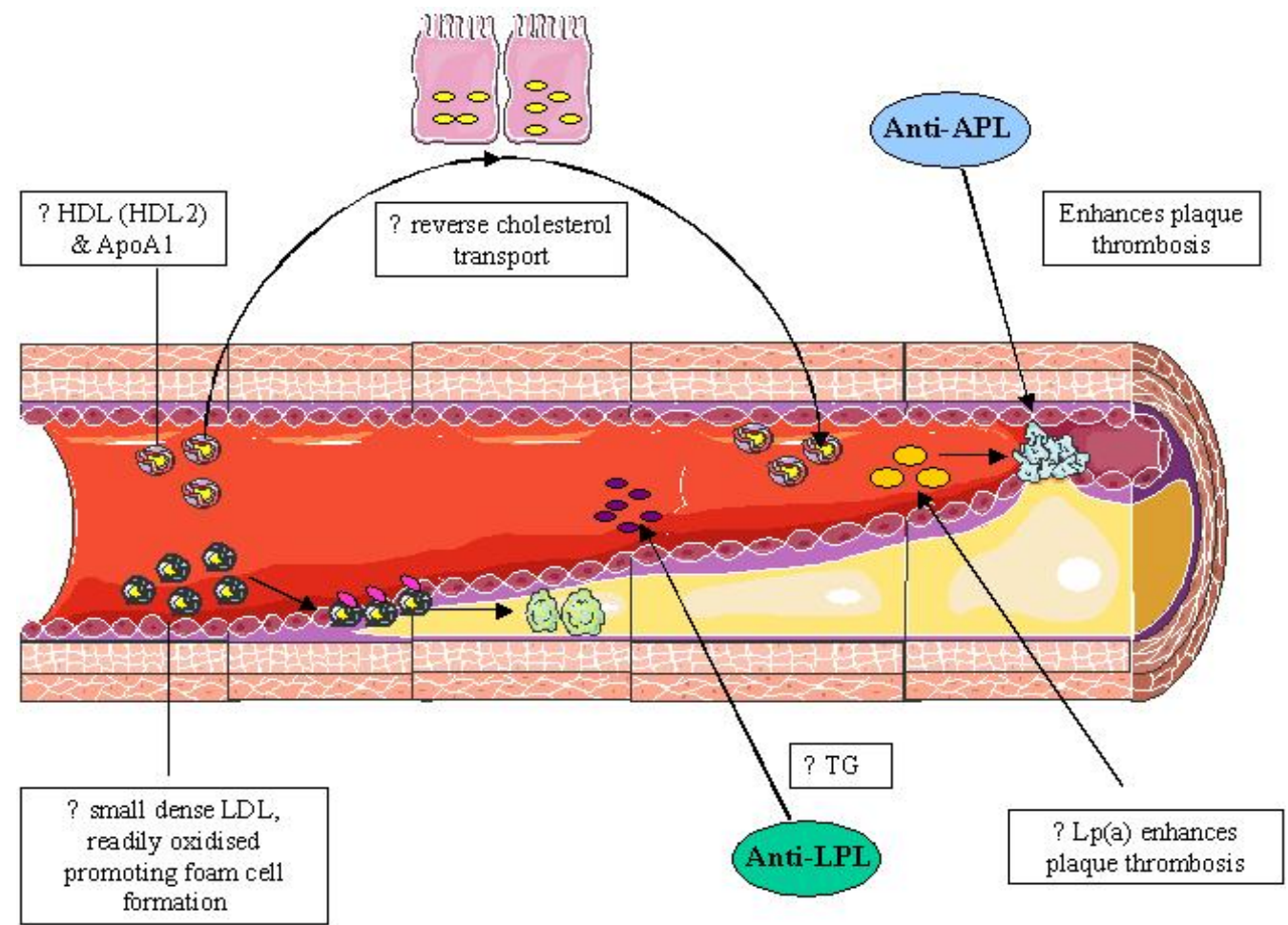

Fig. (5). Common changes in the lipid profile amongst the autoimmune rheumatic disease and their impact on atherosclerotic plaque formation. LDL: Low density lipoproteins, TG: Triglycerides, Lp(a): Lipoprotein (a), Anti-LPL: anti-Lipoprotein Lipase, HDL: high density lipoproteins, ApoA1: Apolipoprotein A1, Anti-APL: anti phospholipid.

sive agents, which are broadly divided in to glucocorticoids (GCs), disease modifying anti-rheumatic drugs (DMARDs), and biologic agents (e.g. anti-TNF). However, the use of these agents differs significantly between conditions due to efficacy, drug licensing, and side effects. Many of these medications alter the lipid profile with the most widely reported change being an elevation in HDL levels [49, 149151]. The most likely mechanism to account for such changes in the lipid profile is generic suppression of inflammation. However, some medications have been shown to exert drug specific effects on the lipid profile. For example, Hydroxychloroquine (HCQ), a DMARD used in the management of RA and SLE, has been reported to produce a less atherogenic lipid profile by lowering TC, LDL and TG and increasing HDL levels $[152,153]$. The advent of newer 'potent' biologic agents offering rapid anti-inflammatory effects has sparked interest surrounding their effect on the lipid profile. However, due to the contraindications of anti-TNF use in SLE patients, most of the data attempting to address this issue has been based in RA patients. The available data demonstrates an increase in TC and HDL levels, with out an overall change in the atherogenic index (TC:HDL) [151, 154]. Thus again potentially reflecting a reversal of the previously inflammatory-mediated suppression of the lipid profile. Despite these findings, very little data exists regarding the more intricate effects of these drugs on lipids, such as lipid subfractions, lipid modifications (e.g. LDL oxidation) and lipid function, and the impact that these may have on cardiovascular risk.

\section{CONCLUSION}

Autoimmunity plays a major role in the development of dyslipidaemia and atherosclerotic plaque formation in many rheumatological conditions. The mechanisms underlying these changes include the interplay of inflammation and auto-antibody formation. Although the pattern of dyslipidaemia appears to differ between the autoimmune rheumatological diseases outlined in this review, many of the underlying mechanisms are similar (Fig. 5). Thus treatment options to reduce CVD risk amongst these conditions share a common theme, with the use of disease-modifying antiinflammatory medications paramount to all.

\section{ABBREVIATIONS}

$\begin{array}{ll}\text { RA } & =\text { Rheumatoid arthritis } \\ \mathrm{SLE} & =\text { Systemic lupus erythematosus } \\ \mathrm{CVD} & =\text { Cardiovascular disease } \\ \mathrm{LDL} & =\text { Low-density lipoprotein } \\ \mathrm{APS} & =\text { Anti-phospholipid syndrome } \\ \mathrm{PSS} & =\text { Primary Sjogrens syndrome } \\ \mathrm{SSc} & =\text { Systemic sclerosis } \\ \mathrm{NO} & =\text { Nitric oxide } \\ \text { eNOS } & =\text { Endothelial nitric oxide synthase } \\ \mathrm{TG} & =\text { Triglyceride } \\ \text { Lp(a) } & =\text { Lipoprotein (a) } \\ \text { OxLDL } & =\text { Oxidised low-desnsity lipoproteins } \\ \text { ApoB } & =\text { ApolipoproteinB } \\ \text { HDL } & =\text { High-desnity lipoproteins } \\ \text { DMARDs } & =\text { Disease modifying anti-rheumatic drugs }\end{array}$




$\begin{array}{ll}\text { GC } & =\text { Glucocorticoids } \\ \text { NHANES } & =\text { National Health and Nutrition Examination } \\ \text { ApoA1 } & =\text { Apolipoprotein A1 } \\ \text { PAI-1 } & =\text { Plasminogen activator inhibitor } \\ \text { CRP } & =\text { C reactive protein } \\ \text { TC } & =\text { Total cholesterol } \\ \text { TNF } & =\text { Tumour necrosis factor } \\ \text { IL } & =\text { Interleukin } \\ \text { ROS } & =\text { Reactive oxygen species } \\ \text { LPL } & =\text { Lipoprotein lipase } \\ \text { NMR } & =\text { Nuclear magnetic resonance } \\ \text { DsDNA } & =\text { Double stranded DNA } \\ \text { ESR } & =\text { Erythrocyte sedimentation rate } \\ \text { IMT } & =\text { Intima-media thickness } \\ \text { HCQ } & =\text { Hydroxychloroquine }\end{array}$

\section{COMPETING INTERESTS}

The Authors declare that they have no competing interests

\section{AUTHORS CONTRIBUTIONS}

$\begin{array}{ll}\text { Tracey E Toms } & \begin{array}{l}\text { Analysis and interpretation of } \\ \text { data, drafting manuscript, ap- } \\ \text { proval of final version to be pub- } \\ \text { lished }\end{array} \\ \text { Vasilieos F Panoulas : } & \begin{array}{l}\text { Acquisition of data, analysis and } \\ \text { interpretation of data, Approval of } \\ \text { final version to be published }\end{array} \\ \text { Goerge D Kitas } & : \begin{array}{l}\text { Substantial contributions to the } \\ \text { conception and design, revision of } \\ \text { draft manuscript, approval of final } \\ \text { version to be published }\end{array}\end{array}$

\section{ACKNOWLEDGEMENTS}

This work is supported by an Arthritis Research Campaign Clinical Fellowship grant (grant number 18848 to T.E.T), and an Arthritis Research Campaign infrastructure support grant (grant number 17682, given to the Dudley Group of Hospitals NHS Foundation Trust, Department of Rheumatology). Dr Vasileios F. Panoulas is supported by a PhD scholarship from Empirikion Institute, Athens, Greece.

\section{REFERENCE}

[1] Kitas GD, Erb N. Tackling ischaemic heart disease in rheumatoid arthritis. Rheumatology 2003; 42: 607-13.

[2] Manzi S, Meilahn EN, Rairie JE, et al. Age-specific incidence rates of myocardial infarction and angina in women with systemic lupus erythematosus: comparison with the Framingham Study. Am J Epidemiol 1997; 145: 408-15.

[3] Van Doornum S, McColl G, Wicks IP. Accelerated atherosclerosis: an extraarticular feature of rheumatoid arthritis? Arthritis Rheum 2002; 46: 862-73.

[4] Executive Summary of The Third Report of The National Cholesterol Education Program (NCEP) Expert Panel on Detection,
Evaluation, And Treatment of High Blood Cholesterol In Adults (Adult Treatment Panel III). JAMA 2001; 285: 2486-97.

[5] Libby P, Ridker PM, Maseri A. Inflammation and atherosclerosis. Circulation 2002; 105: 1135-43.

[6] Ross R, Glomset JA. Atherosclerosis and the arterial smooth muscle cell: Proliferation of smooth muscle is a key event in the genesis of the lesions of atherosclerosis. Science 1973; 180: 1332-9.

[7] Loscalzo J. Endothelium, nitric oxide and atherosclerosis: From basic mechanisms to clinical implications. Circulation 2000; e21: 201.

[8] Cai H, Harrison DG. Endothelial dysfunction in cardiovascular diseases: the role of oxidant stress. Circ Res 2000; 87: 840-4.

[9] Landmesser U, Dikalov S, Price SR, et al. Oxidation of tetrahydrobiopterin leads to uncoupling of endothelial cell nitric oxide synthase in hypertension. J Clin Invest 2003; 111: 1201-9.

[10] Tiefenbacher CP, Bleeke T, Vahl C, Amann K, Vogt A, Kubler W. Endothelial dysfunction of coronary resistance arteries is improved by tetrahydrobiopterin in atherosclerosis. Circulation 2000; 102: 2172-9.

[11] Gerrity RG. The role of the monocyte in atherogenesis: II. Migration of foam cells from atherosclerotic lesions. Am J Pathol 1981; 103: 191-200.

[12] Mehta JL, Li DY, Chen HJ, Joseph J, Romeo F. Inhibition of LOXI by statins may relate to upregulation of eNOS. Biochem Biophys Res Commun 2001; 289: 857-61.

[13] Kugiyama K, Doi H, Motoyama T, et al. Association of remnant lipoprotein levels with impairment of endothelium-dependent vasomotor function in human coronary arteries. Circulation 1998; 97: 2519-26.

[14] Kugiyama K, Motoyama T, Doi H, et al. Improvement of endothelial vasomotor dysfunction by treatment with alpha-tocopherol in patients with high remnant lipoprotein levels. J Am Coll Cardiol 1999; 33: 1512-8.

[15] Schaich MP, John S, Langenfield MRW. Does lipoprotein (a) impair endothelial function. J Am Coll Cardio 1998; 31: 359-65.

[16] Schillinger M, Mlekusch W, Haumer M, Sabeti S, Maca T, Minar E. Relation of small artery compliance and lipoprotein (a) in patients with atherosclerosis. Am J Hypertens 2002; 15: 980-85.

[17] van Leuven SI, Franssen R, Kastelein JJ, Levi M, Stroes ESG, Tak PP. Systemic inflammation as a risk factor for atherothrombosis. Rheumatology 2008; 47: 3-7.

[18] Wever RMF, Luscher TF, Cosentino F, Rabenlink TJ. Atherosclerosis and the two faces of endothelial nitric oxide synthase. Circulation 1998; 97: 108-12.

[19] Letinger N. Oxidised phospholipids as modulators of inflammation in atehrosclerosis. Curr Opin Lipidol 2003; 14: 421-30.

[20] Skalen K, Gustafsson M, Rydberg EK, et al. Subendothelial retention of atherogenic lipoproteins in early atherosclerosis. Nature 2002; 417: 750-4.

[21] Massberg S, Brand K, Gruner S, et al. A critical role of platelet adhesion in the initiation of atherosclerotic lesion formation. J Exp Med 2002; 196: 887-96.

[22] Henn V, Slupsky JR, Grafe M, et al. CD40 ligand on activated platelets triggers an inflammatory reaction of endothelial cells. $\mathrm{Na}-$ ture 1998; 391: 591-4.

[23] Stary HC, Chandler AB, Glagov S, et al. A definition of initial, fatty streak, and intermediate lesions of atherosclerosis. A report from the Committee on Vascular Lesions of the Council on Arteriosclerosis, American Heart Association. Circulation 1994; 89: 2462-78.

[24] Toschi V, Gallo R, Lettino M, et al. Tissue factor modulates the thrombogenicity of human atherosclerotic plaques. Circulation 1997; 95: 594-9.

[25] Moreno PR, Falk E, Palacios IF, Newell JB, Fuster V, Fallon JT. Macrophage infiltration in acute coronary syndromes. Implications for plaque rupture. Circulation 1994; 90: 775-8.

[26] Symmons D, Turner G, Webb R, et al. The prevalence of rheumatoid arthritis in the United Kingdom: new estimates for a new century. Rheumatology 2002; 41: 793-800.

[27] Pincus T, Callahan LF. Taking mortality in rheumatoid arthritis seriously-predictive markers, socioeconomic status and comorbidity. J Rheumatol 1986; 13: 841-5.

[28] Avina-Zubieta JA, Choi HK, Sadatsafavi M, Etminan M, Esdaile JM, Lacaille D. Risk of cardiovascular mortality in patients with rheumatoid arthritis: a meta-analysis of observational studies. Arthritis Rheum 2008; 59: 1690-7. 
[29] Mutru O, Laasko M, Isomaki H, Koota K. Cardiovascular mortality in patients with rheumatoid arthritis. Br Med J 1989; 290: 1797-9.

[30] Stevens RJ, Douglas KM, Saratzis AN, Kitas GD. Inflammation and atherosclerosis in rheumatoid arthritis. Expert Rev Mol Med 2005; $7:$ : $1-24$.

[31] Wallberg-Jonsson S, Ohman ML, Dahlqvist SR. Cardiovascular morbidity and mortality in patients with seropositive rheumatoid arthritis in Northern Sweden. J Rheumatol 1997; 24: 445-51.

[32] Wislowska M, Sypula S, Kowalick I. Echocardiographic findings, 24 hour electrocardiographic Holter monitoring in patients with rheumatoid arthritis according to Steinbrocker's criteria, functional index, value of Waaler-Rose titre and duration of disease. Clin Rheumatol 1998; 17: 377.

[33] Aubry MC, Maradit-Kremers H, Reinalda MS, Crowson CS, Edwards WD, Gabriel SE. Differences in atherosclerotic coronary heart disease between subjects with and without rheumatoid arthritis. J Rheumatol 2007; 34: 937-42.

[34] Maradit-Kremers H, Crowson CS, Nicola PJ, et al. Increased unrecognised coronary heart disease and sudden death in rheumatoid arthritis: a population-based cohort study. Arthritis Rheum 2005; 52: 402-11.

[35] Panoulas VF, Douglas KM, Milionis HJ, et al. Prevalence and associations of hypertension and its control in patients with rheumatoid arthritis. Rheumatology 2007; 46: 1477-82.

[36] Panoulas VF, Metsios GS, Pace AV, et al. Hypertension in rheumatoid arthritis. Rheumatology 2008; 47: 1286-98.

[37] Metsios GS, Stavropoulos-Kalinglou A, Panoulas VF, et al. Association of physical inactivity with increased cardiovascular risk in patients with rheumatoid arthritis. Eur J Cardiovascular Prev Rehab 2009; 16: 188-94.

[38] Stavropoulos-Kalinglou A, Metsios GS, Panoulas VF, et al. Associations of obesity with modifiable risk factors for the development of cardiovascular disease in patients with rheumatoid arthritis. Ann Rheum Dis 2009; 68: 242-5.

[39] Stavropoulos-Kalinoglou A, Metsios GS, Koutedakis Y, et al. Redefining overweight and obesity in rheumatoid arthritis patients. Ann Rheum Dis 2007; 66: 1316-21.

[40] Lopez-Olivo MA, Gonzalez-Lopez L, Garcia-Gonzalez A, et al. Factors associated with hyperhomocysteinaemia in Mexican patients with rheumatoid arthritis. Scand J Rheumatol 2006; 35: $112-6$.

[41] Ingegnoli F, Fantini F, Giulio Favalli E, et al. Inflammatory and prothrombotic biomarkers in patients with rheumatoid arthritis: Effects of tumour necrosis factor-alpha blockade. J Autoimmun 2008; 31: 175-9.

[42] Ridker PM. High-sensitivity C-reactive protein: potential adjunct for global risk assessment in the primary prevention of cardiovascular disease. Circulation 2001; 103: 1813-8.

[43] Willerson JT, Ridker PM. Inflammation as a cardiovascular risk factor. Circulation 2004; 109: (21 suppl 1): 112-10.

[44] Panoulas VF, Nikas SN, Smith JP, et al. Lymphotoxin $252 \mathrm{~A}>\mathrm{G}$ polymorphism is common and associates with myocardial infarction in patients with rheumatoid arthritis. Ann Rheum Dis 2008; 67: $1550-6$.

[45] Swanberg M, Lidman O, Padyukov L, et al. MHC2TA is associated with differential MHC molecule expression and suscepatbility to rheumatoid arthritis, multiple sclerosis and myocardial infarction. Nat Genet 2005; 37: 486-94.

[46] Dessein PH, Joffe BI, Stanwix A, Botha AS, Moomal Z. The acute phase response does not fully predict the presence of insulin resistance and dyslipidaemia in inflammatory arthritis. J Rheumatol 2002; 29: 462-6.

[47] Kavanaugh A. Dyslipoproteinaemia in a subset of patients with rheumatoid arthritis. Ann Rheum Dis 1994; 53: 551-2.

[48] Park YB, Lee SK, Lee WK, et al. Lipid profiles in untreated patients with rheumatoid arthritis. J Rheumatol 1999; 26: 1701-4.

[49] Peters MJ, Vis M, van Halm VP, et al. Changes in lipid profile during infliximab and corticosteroid treatment in rheumatoid arthritis. Ann Rheum Dis 2007; 66: 958-61.

[50] van Halm VP, Nielen MM, Nurmohamed MT, et al. Lipids and inflammation: serial measurements of the lipid profile of blood donors who later developed rheumatoid arthritis. Ann Rheum Dis 2007; 66: 184-8.

[51] Nurmohamed MT. Atherogenic lipid profiles and its management in patients with rheumatoid arthritis. Vasc Health Risk Manag 2007; 3: 845-52.
[52] Yoo HW. Dyslipoproteinemia in patients with active rheumatoid arthritis: Effects of disease activity, sex, and menopausal status on lipid profiles. J Rheumatol 2004; 31: 1746-53.

[53] Kelly CA. Extra-articular features of rheumatoid arthritis. Medicine 2002; 30: 48-9.

[54] Choi HK, Seeger JD. Lipid profiles among US elderly with untreated rheumatoid arthritis--the Third National Health and Nutrition Examination Survey. J Rheumatol 2005; 32: 2311-6.

[55] Toms TE, Symmons PM, Kitas GD. Dyslipidaemia in rheumatoid arthritis: the role of inflammation, drugs, lifestyle and genetic factors. Curr Vasc Pharm 2010; 8(3): 301-26.

[56] Dursunoglu D, Evrengul H, Polat B, et al. Lp(a) lipoprotein and lipids in patients with rheumatoid arthritis: serum levels and relationship to inflammation. Rheumatol Int 2005; 25: 241-5.

[57] Nurmohamed MT, Dijkmans BA. Dyslipidaemia, statins and rheumatoid arthritis. Ann Rheum Dis 2009; 68: 453-5.

[58] Steiner G, Urowitz MB. Lipid profiles in patients with rheumatoid arthritis: mechanisms and the impact of treatment. Sem Arthritis rheum 2009; 38: 372-81

[59] Rantapaa-Dahlqvist S, Wallberg-Jonsson S, Dahlen G. Lipoprotein (a), lipids, and lipoproteins in patients with rheumatoid arthritis. Ann Rheum Dis 1991; 50: 366-8.

[60] Svenson KL, Lithell H, Hallgren R, Selinus I, Vessby B. Serum lipoprotein in active rheumatoid arthritis and other chronic inflammatory arthritides. I. Relativity to inflammatory activity. Arch Intern Med 1987; 147: 1912-6.

[61] Packard CJ, Ford I, Robertson M, et al. Plasma lipoproteins and apolipoproteins as predictors of cardiovascular risk and treatment benefit in the PROspective Study of Pravastatin in the Elderly at Risk (PROSPER). Circulation 2005; 112: 3058-65.

[62] Contois JH, McConnell JP, Sethi AA, et al. Apolipoprotein B and cardiovascular disease risk: position statement from the AACC Lipoproteins and Vascular Diseases Division Working Group on Best Practices. Clin Chem 2009; 55: 407-19.

[63] Georgiadis AN, Voulgari PV, Argyropoulou MI, et al. Early Treatment Reduces the Cardiovascular Risk Factors in Newly Diagnosed Rheumatoid Arthritis Patients. Semin Arthritis Rheum 2008; 38: 13-9.

[64] Garcia-Gomez C, Nolla JM, Valverde J, Gomez-Gerique JA, Castro MJ, Pinto X. Conventional Lipid Profile and Lipoprotein(a) Concentrations in Treated Patients with Rheumatoid Arthritis. J Rheumatol 2009; 36: 1365-70.

[65] Wilson PW, D'Agostino RB, Levy D, Belanger AM, Silbershatz H, Kannel WB. Prediction of coronary heart disease using risk factor categories. Circulation 1998; 97: 1837-47.

[66] Kamanli A, Naziroglu M, Aydilek N, Hacievliyagil C. Plasma lipid peroxidation and antioxidant levels in patients with rheumatoid arthritis. Cell Biochem Funct 2004; 22: 53-7.

[67] Stampfer MJ, Sacks FM, Salvini S, Willett WC, Hennekens CH. A prospective study of cholesterol, apolipoproteins, and the risk of myocardial infarction. N Engl J Med 1991; 325: 373-81.

[68] Leu HB, Lin CP, Lin WT, Wu TC, Chen JW. Risk stratification and prognostic implication of plasma biomarkers in nondiabetic patients with stable coronary artery disease: the role of highsensitivity C-reactive protein. Chest 2004; 126: 1032-9.

[69] Fernandez ML, Webb D. The LDL to HDL cholesterol ratio as a valuable tool to evaluate coronary heart disease risk. J Am Coll Nutr 2008; 27: 1-5.

[70] van der Steeg WA, Boekholdt SM, Stein EA, et al. Role of the apolipoprotein B-apolipoprotein A-I ratio in cardiovascular risk assessment: a case-control analysis in EPIC-Norfolk. Ann Intern Med 2007; 146: 640-8.

[71] Choy E, Sattar N. Interpreting lipid levels in the context of highgrade inflammatory states with a focus on rheumatoid arthritis: a challenge to conventional cardiovascular risk actions. Ann Rheum Dis 2009; 68: 460-9.

[72] Bostom AG, Cupples LA, Jenner JL, et al. Elevated plasma lipoprotein(a) and coronary heart disease in men aged 55 years and younger. A prospective study. JAMA 1996; 276: 544-8.

[73] Danesh J, Collins R, Peto R. Lipoprotein(a) and coronary heart disease. Meta-analysis of prospective studies. Circulation 2000; 102: $1082-5$.

[74] Rouy D, Grailhe P, Nigon F, Chapman J, Angles-Cano E. Lipoprotein(a) impairs generation of plasmin by fibrin-bound tissue-type plasminogen activator. In vitro studies in a plasma milieu. Arterioscler Thromb 1991; 11: 629-38. 
[75] Berglund L, Anuurad E. Role of lipoprotein(a) in cardiovascular disease current and future perspectives. J Am Coll Cardiol 2008; 52: $132-4$

[76] Maher VM, Brown BG, Marcovina SM, Hillger LA, Zhao XQ, Albers JJ. Effects of lowering elevated LDL cholesterol on the cardiovascular risk of lipoprotein(a). JAMA 1995; 274: 1771-4.

[77] Lee YH, Choi SJ, Ji JD, Seo HS, Song GG. Lipoprotein(a) and lipids in relation to inflammation in rheumatoid arthritis. Clin Rheumatol 2000; 19: 324-5.

[78] Seriolo B, Paolino S, Sulli A, Fasciolo D, Cutolo M. Effects of anti-TNF-alpha treatment on lipid profile in patients with active rheumatoid arthritis. Ann N Y Acad Sci 2006; 1069: 414-9.

[79] Asanuma Y, Kawai S, Aoshima H, Kaburaki J, Mizushima Y. Serum lipoprotein(a) and apolipoprotein(a) phenotypes in patients with rheumatoid arthritis. Arthritis Rheum 1999; 42: 443-7.

[80] Boerwinkle E, Leffert CC, Lin J, Lackner C, Chiesa G, Hobbs H. Apolipoprotein(a) gene accounts for greater than $90 \%$ of the variation in plasma lipoprotein(a) concentrations. J Clin Invest 1992; 90: 60 .

[81] Utermann G, Kraft HG, Menzel HJ, Hopferwieser T, Seitz C. Genetics of the quantitative $\mathrm{Lp}$ (a) lipoprotein trait. Hum Genet 1988; $78: 46$.

[82] Aldred S, Banks M, Kitas GD, Griffiths HR. Incrceased levels of oxidised LDL in the plasma of rheumatoid patients with cardiovascular disease: consequences for monocyte scavenger receptor uptake of LDL. Rheumatology 2001; 41: 69

[83] James MJ, van Reyk D, Rye KA, et al. Low density lipoprotein of synovial fliud in inflammatory joint disease is mildly oxidised. Lipids 1998; 33: 1115-21.

[84] de Graaf J, Hak-Lemmers HL, Hectors MP, Demacker PN, Hendriks JC, Stalenhoef AF. Enhanced susceptibility to in vitro oxidation of the dense low density lipoprotein subfraction in healthy subjects. Arterioscler Thromb 1991; 11: 298-306.

[85] Lamarche B, Moorjani S, Cantin B, Dagenais GR, Lupien PJ, Despres JP. Associations of HDL2 and HDL3 subfractions with ischemic heart disease in men. Prospective results from the Quebec Cardiovascular Study. Arterioscler Thromb Vasc Biol 1997; 17: 1098-105.

[86] Hurt-Camejo E, Paredes S, Masana L, et al. Elevated levels of small, low-density lipoprotein with high affinity for arterial matrix components in patients with rheumatoid arthritis: possible contribution of phospholipase A2 to this atherogenic profile. Arthritis Rheum 2001; 44: 2761-7.

[87] Popa C, van Tits LJH, Lemmers HLM, et al. Anti-inflammatory therapy with tumour necrosis factor alpha inhibitors improves highdensity lipoprotein cholesterol antioxidative capacity in rheumatoid arthritis patients. Ann.Rheum Dis 2009; 68: 868-72.

[88] Schanberg LE, Sandborg C, Barnhart HX, et al. Premature atherosclerosis in pediatric systemic lupus erythematosus: Risk factors for increased carotid intima-media thickness in the atherosclerosis prevention in pediatric lupus erythematosus cohort. Arthritis Rheum 2009; 60: 1496-507.

[89] El-Magadmi M, Bodill H, Ahmed Y, et al. Systemic lupus erythematosus: an independant risk factor for endothelial dysfunction in women. Circulation 2004; 110: 399-404.

[90] Zeller CB, Appenzeller S. Cardiovascular disease in systemic lupus erythematosus: the role of traditional and lupus related risk factors. Curr Cardiol Rev 2008; 4: 116-22.

[91] Ames PR, Margarita A, Alves JD. Antiphospholipid Antibodies and Atherosclerosis: Insights from Systemic Lupus Erythematosus and Primary Antiphospholipid Syndrome. Clin Rev Allergy Immunol 2008; 37: 29-35.

[92] Frostegard J. SLE, atherosclerosis and cardiovascular disease. J Intern Med 2005; 257: 485-95.

[93] Nuttall SL, Heaton S, Piper MK, Martin U, Gordon C. Cardiovascular risk in systemic lupus erythematosus--evidence of increased oxidative stress and dyslipidaemia. Rheumatology 2003; 42: 75862.

[94] Borba EF, Bonfa E. Dyslipoproteinemias in systemic lupus erythematosus: influence of disease, activity, and anticardiolipin antibodies. Lupus 1997; 6: 533-9.

[95] de Carvalho JF, Bonfa E, Borba EF. Systemic lupus erythematosus and "lupus dyslipoproteinemia". Autoimmun Rev 2008; 7: 246-50.

[96] Chung CP, Oeser A, Solus J, et al. Inflammatory mechanisms affecting the lipid profile in patients with systemic lupus erythematosus. J Rheumatol 2007; 34: 1849-54.
[97] Kashef S, Ghaedian MM, Rajaee A, Ghaderi A. Dyslipoproteinemia duering the active course of systemic lupus erythematosus in assocaition with anti-double-stranded DNA (anti-dsDNA) antibodies. Rheumatol Int 2006; 27: 235-41.

[98] Asanuma Y, Chung CP, Oeser A, et al. Increased concentration of proatherogenic inflammatory cytokines in systemic lupus erythematosus: relationship to cardiovascular risk factors. J Rheumatol 2006; 33: 539-45.

[99] Svenungsson E, Gunnarsson I, Fei GZ, Lundberg IE, Klareskog L, Frostegard J. Elevated triglycerides and low levels of high-density lipoprotein as markers of disease activity in association with upregulation of the tumour necrosis factor alpha/tumour necrosis factor receptor system in systemic lupus erythematosus. Arthritis Rheum 2003; 48: 2533-40.

[100] de Carvalho JF, Borba EF, Viana VS, Bueno C, Leon EP, Bonfa E. Anti-lipoprotein lipase antibodies: a new player in the complex atherosclerotic process in systemic lupus erythematosus? Arthritis Rheum 2004; 50: 3610-5.

[101] Ehnholm C, Aho K, Huttunen JK, et al. Effect of interferon on plasma lipoproteins and on the activity of postheparin plasma lipases. Arteriosclerosis 1982; 2: 68-73.

[102] Reichlin M, Fesmire J, Quintero-Del-Rio AI, Wolfson-Reichlin M. Autoantibodies to lipoprotein lipase and dyslipidemia in systemic lupus erythematosus. Arthritis Rheum 2002; 46: 2957-63.

[103] Ames PR, Alves J, Murat I, Isenberg DA, Nourooz-Zadeh J. Oxidative stress in systemic lupus erythematosus and allied conditions with vascular involvement. Rheumatology 1999; 38: 529-34.

[104] McMahon M, Grossman J, Skaggs B, et al. Dysfunctional proinflammatory high-density lipoproteins confer increased risk of atherosclerosis in women with systemic lupus erythematosus. Arthritis Rheum 2009; 60: 2428-37.

[105] Love PE, Santoro SA. Antiphospholipid antibodies: anticardiolipin and the lupus anticoagulant in systemic lupus erythematosus (SLE) and in non-SLE disorders. Prevalence and clinical significance. Ann Intern Med 1990; 112: 682-98.

[106] Wahl DG, Guillemin F, de Maistre E, Perret C, Lecompte T, Thibaut G. Risk for venous thrombosis related to antiphospholipid antibodies in systemic lupus erythematosus-a meta-analysis. Lupus 1997; 6: 467-73.

[107] Lahita RG, Rivkin E, Cavanagh I, Romano P. Low levels of total cholesterol, high-density lipoprotein, and apolipoprotein A1 in association with anticardiolipin antibodies in patients with systemic lupus erythematosus. Arthritis Rheum 1993; 36: 1566-74.

[108] Vaarala O, Alfthan G, Jauhiainen M, Leirisalo-Repo M, Aho K, Palosuo T. Crossreaction between antibodies to oxidised lowdensity lipoprotein and to cardiolipin in systemic lupus erythematosus. Lancet 1993; 341: 923-5.

[109] Damoiseaux J, Jeyasekharan AD, Theunissen R, Tervaert JW. Cross-reactivity of $\operatorname{IgM}$ and $\mathrm{IgG}$ anticardiolipin antibodies with oxidised-low density lipoproteins. Ann N Y Acad Sci 2005; 1050: 163-9.

[110] Kobayashi K, Kishi M, Atsumi T, et al. Circulating oxidised low density lipoprotein forms with B2-glycoprotein I: implication as an atherogenic autoantigen. J Lipid Res 2003; 10: 1196.

[111] Chung CP, Oeser A, Raggi P, et al. Lipoprotein subclasses and particle size determined by nuclear magnetic resonance spectroscopy in systemic lupus erythematosus. Clin Rheumatol 2008; 27 : 1227-33.

[112] Hua X, Su J, Svenungsson E, et al. Dyslipidaemia and lipoprotein pattern in systemic lupus erythematosus (SLE) and SLE-related cardiovascular disease. Scand J Rheumatol 2009; 38: 184-9.

[113] Ettinger WH, Goldberg AP, Applebaum-Bowden D, Hazzard WR. Dyslipoproteinaemia in systemic lupus erythematosus. Effect of corticosteroids. Am J Med 1987; 83: 503-8.

[114] Forminga F, Meco JF, Pinto X, Jacob J, Moga I, Pujol R. Lipid and lipoprotein levels in premenopausal systemic lupus erythematosus patients. Lupus 2001; 10: 359-63.

[115] Borba EF, Santos RD, Bonfa AE, et al. Lipoprotein (a) levels in systemic lupus erythematosus. J Rheumatol 1994; 21: 220-3.

[116] Sari RA, Polat MF, Taysi S, Bakan E, Capoglu I. Serum lipoprotein (a) levels and its clinical significance in patients with systemic lupus erythematosus. Clin Rheumatol 2002; 21: 520-4.

[117] Kawai S, Mizushima Y, Kaburaki J. Increased serum lipoprotein(a) levels in systemic lupus erythematosus with myocardial and cerebral infarctions. J Rheumatol 1995; 22: 1210-1. 
[118] Peros E, Geroldi D, Bugatti S, et al. Analysis of the apolipoprotein(a) size polymorphism in patients with systemic lupus erythematosus. Int J Mol Med 2005; 15: 661-5.

[119] MacGregor AJ, Betteridge DJ, Isenberg DA. Serum lipoprotein (a) in systemic lupus erythematosus. Rheumatology 1990: 103-37.

[120] Forminga F, Meco JF, Pinto X, Jacob J, Moga I, Pujol R. Lipid and lipoprotein levels in premenopausal systemic erythematosus patients. Lupus 2001; 10: 359-63.

[121] Ettinger WHJr, Hazzard WR. Elevated apolipoprotein-B levels in corticosteroid-treated patients with systemic lupus erythematosus. J Clin Endo Metab 1988; 67: 425-8.

[122] Hughes GR, Harris NN, Gharavi AE. The anticardiolipin syndrome. J Rheumatol 1986; 13: 486-9.

[123] Ames PR, Sokoll K, Weston M, Margarita A, Brancaccio V. Atherosclerosis in primary antiphospholipid syndrome. Ann Rheum Dis 2004; 63: 610-1.

[124] Vaarala O. Antiphospholipid antibodies and myocardial infarction. Lupus 1998; 7 Suppl 2: S132-4.

[125] Zuckerman E, Toubi E, Shiran A, et al. Anticardiolipin antibodies and acute myocardial infarction in non-systemic lupus erythmatosus patients: a controlled prospective study. Am J Med 1996; 101: 381-6.

[126] Ames PR, Margarita A, Sokoll KB, Weston M, Brancaccio V. Premature atherosclerosis in primary antiphospholipid syndrome: preliminary data. Ann Rheum Dis 2005; 64: 315-7.

[127] Soltesz P, Der H, Veres K, et al. Immunological features of primary anti-phospholipid syndrome in connection with endothelial dysfunction. Rheumatology 2008; 47: 1628-34.

[128] Vlachoyiannopoulos PG, Kanellopoulos PG, Ioannidis JP, Tektonidou MG, Mastorakou I, Moutsopoulos HM. Atherosclerosis in premenopausal women with antiphospholipid syndrome and systemic lupus erythematosus: a controlled study. Rheumatology 2003; 42: 645-51.

[129] Medina G, Casaos D, Jara LJ, et al. Increased carotid artery intimamedia thickness may be associated with stroke in primary antiphospholipid syndrome. Ann Rheum Dis 2003; 62: 607-10.

[130] Vaudo G, Bocci EB, Shoenfeld Y, et al. Precocious intima-media thickening in patients with primary Sjogren's syndrome. Arthritis Rheum 2005; 52: 3890-7.

[131] Lodde BM, Sankar V, Kok MR, Leakan RA, Tak PP, Pillemer SR. Serum lipid levels in Sjogren's syndrome. Rheumatology 2006; 45: 481-4.

[132] Gerli R, Bartoloni BE, Vaudo G, Marchesi S, Vitali C, Shoenfeld Y. Traditional cardiovascular risk factors in primary Sjogren's syndrome--role of dyslipidaemia. Rheumatology 2006; 45: 1580-1.

[133] Cutolo M, Sulli A, Secchi ME, Paolino S, Pizzorni C. Nailfold capillaroscopy is useful for the diagnosis and follow-up of autoimmune rheumatic diseases. A future tool for the analysis of microvascular heart involvement? Rheumatology 2006; 45 Suppl 4: iv43-6.

[134] Secchi ME, Sulli A, Pizzorni C, Cutolo M. Nailfold capillaroscopy and blood flow laser-doppler analysis of the microvascular damage in systemic sclerosis: preliminary results. Reumatismo 2009; 61: 34-40.

[135] Ho M, Veale D, Eastmond C, Nuki G, Belch J. Macrovascular disease and systemic sclerosis. Ann Rheum Dis 2000; 59: 39-43.

[136] Bryan C, Howard Y, Brennan P, Black C, Silman A. Survival following the onset of scleroderma: results from a retrospective inception cohort study of the patients population. Br J Rheumatol 1996; 35: 1122-6.

[137] Fowkes FGR, Housley E, Cawood EHH, Macintyre CCA, Ruckley CV, Prescott RJ. Edinburgh artery study: Prevalence of asympto- matic and symptomatic peripheral arterial disease in the general population. Int J Epidemiol 1991; 20: 384-92.

[138] Veale DJ, Collidge TA, Belch JJ. Increased prevalence of symptomatic macrovascular disease in systemic sclerosis. Ann Rheum Dis 1995; 54: 853-5.

[139] Hettema ME, Zhang D, de Leeuw K, Steinstra Y, Kallenberg CG, Bootsma H. Early atherosclerosis in systemic sclerosis and its relation to disease or traditional risk factors. Arthritis Res Ther 2008; 10: R49.

[140] Szucs G, Timar O, Szekanecz Z, et al. Endothelial dysfunction precedes atherosclerosis in systemic sclerosis - relevance for prevention of vascular complications. Rheumatology 2007; 46: 759-62.

[141] Cypiene A, Laucevicius A, Venalis A, et al. The impact of systemic sclerosis on arterial wall stiffness parameters and endothelial function. Clin Rheumatol 2008; 27: 1517-22.

[142] Cardillo C, Campia U, Kilcoyne CM, Bryant MB, Panza JA. Improved endothelin-dependant vasodilatation after blockade of endothelin receptors in patients with essential hypertension. Circulation 2002; 105: 452-6.

[143] Kotyla PJ, Lewicki M, Kucharz EJ. Hypothyroidism contributes to increased triglyceride levels among patients with systemic sclerosis. J Rheumatol 2006; 33: 827.

[144] Kodera M, Hayakawa I, Komura K, et al. Anti-lipoprotein lipase antibody in systemic sclerosis: association with elevated serum triglyceride concentrations. J Rheumatol 2005; 32: 629-36.

[145] Bruckdorfer KR, Hillary JB, Bunce T, Vancheeswaran R, Black CM. Increased susceptibility to oxidation of low-density lipoproteins isolated from patients with systemic sclerosis. Arthritis Rheum 1995; 38: 1060-7.

[146] Lippi G, Caramaschi P, Montaganana M, Salvagno GL, Volpe A, Guidi G. Lipoprotein (a) and the lipid profile in patients with systemic sclerosis. Clin Chimica Acta 2006; 364: 345-8.

[147] Andersen GA, Caidahi K, Kazzam E, et al. Correlation between increased nitric oxide production and markers of endothelial activation in systemic sclerosis: Findings with the soluble adhesion molecules E-selectin, intracellular adhesion molecule 1, and vascular cell adhesion molecule 1. Arthritis Rheum 2001; 43: 1085-93.

[148] Gruschwitz MS, Hornstein OP, von Den Driesch P. Correlation of soluble adhesion molecules in the peripheral blood of scleroderma patients with their in situ expression and with disease activity. Arthritis Rheum 1995; 38: 184-9.

[149] Hodis HN, Quismorio FP, Wickham E, Blankenhorn DH. The lipid, lipoprotein, and apolipoprotein effects of hydroxychloroquine in patients with systemic lupus erythematosus. J Rheumatol 1993; 20: 661-5.

[150] Popa C, van den Hoogen FH, Radstake TR, et al. Modulation of lipoprotein plasma concentrations during long-term anti-TNF therapy in patients with active rheumatoid arthritis. Ann Rheum Dis 2007; 66: 1503-7.

[151] Tam LS, Tomlinson B, Chu TT, Li TK, Li EK. Impact of TNF inhibition on insulin resistance and lipids levels in patients with rheumatoid arthritis. Clin Rheumatol 2007; 26: 1495-8.

[152] Munro R, Morrison E, McDonald AG, Hunter JA, Madhok R, Capell HA. Effect of disease modifying agents on the lipid profile of patients with rhuematoid arthritis. Ann Rheum Dis 1997; 56: 374-7.

[153] Tam LS, Gladman DD, Hallatt DC, Rahman P, Urowitz MB. Effect of antimalarial agents on the fasting lipid profile in systemic lupus erythematosus. J Rheumatol 2000; 27: 2142-5.

[154] Soubrier M, Jouanel P, Mathieu S, et al. Effects of anti-tumor necrosis factor therapy on lipid profile in patients with rheumatoid arthritis. Joint Bone Spine 2008; 75: 22-4. 